\title{
Role of the Gas6/TAM System as a Disease Marker and Potential Drug Target
}

\author{
Pier Paolo Sainaghi $\mathbb{D},,^{1,2,3}$ Mattia Bellan $\left(\mathbb{D},,^{1,2,3}\right.$ and Alessandra Nerviani $\mathbb{D}^{3,4}$ \\ ${ }^{1}$ Department of Translational Medicine, Università del Piemonte Orientale UPO, Novara, Italy \\ ${ }^{2}$ Division of Rheumatology, CAAD (Center for Translational Research on Autoimmune and Allergic Diseases) "AOU Maggiore \\ della Carità", Novara, Italy \\ ${ }^{3} I R C A D$, Interdisciplinary Research Center of Autoimmune Diseases, Novara, Italy \\ ${ }^{4}$ Experimental Medicine and Rheumatology, William Harvey Research Institute and Barts and The London School of Medicine \\ and Dentistry, Queen Mary University of London, London, UK
}

Correspondence should be addressed to Mattia Bellan; mattia.bellan@med.uniupo.it

Received 22 June 2020; Accepted 22 June 2020; Published 18 January 2021

Copyright (c) 2021 Pier Paolo Sainaghi et al. This is an open access article distributed under the Creative Commons Attribution License, which permits unrestricted use, distribution, and reproduction in any medium, provided the original work is properly cited.

Growth arrest-specific 6 (Gas6) is a gene cloned in 1993 [1] encoding for a vitamin K-dependent protein expressed in different tissues [1-3]. Its biological activities are mediated by the interaction with three tyrosine kinase receptors: Tyro3, Axl, and MerTK, which are commonly and collectively abbreviated as TAM [4]. These receptors share a common feature: their extracellular domain is proteolytically cleaved and released in a soluble form (sTyro3, sAxl, and sMer; sTAM collectively) and acts as a decoy receptor; consistently, the shedding of the ectodomain entails the reduction of transmembrane receptors available for the ligands $[5,6]$.

Different activities have been attributed to Gas6/TAM interaction: it has been shown to act on platelet function [7], to regulate cell growth [8], to mediate the phagocytosis of apoptotic bodies [9], and to switch off inflammatory response [10].

On these bases, Gas6 and sTAM role as biomarkers has been explored and partially validated in several human diseases, particularly in those where fibrosis and inflammation are relevant [11]. In this context, the diagnostic performance of Gas6 has been evaluated in neuroinflammatory [12-14] and neurodegenerative disorders [15]; moreover, Gas6 and the circulating forms of TAM receptors have been observed to be increased in the plasma of patients affected by systemic lupus erythematosus, being predictive of disease severity $[16,17]$. Among other inflammatory disorders, Gas6 and TAM system receptors have been also proposed as disease biomarkers in rheumatoid arthritis [18] and Sjogren's syndrome [19].

Consistently, being related to fibrosis and inflammation, Gas6 and sAxl have been found increased in the plasma of patients affected by liver cirrhosis [20], a condition in which the overly exuberant accumulation of extracellular matrix proteins commonly triggered by chronic injury of the hepatic parenchyma with an inflammatory component leads to hepatic fibrosis with a structural and functional disruption. In this context, since their plasmatic levels are predictive of the development of complications of chronic liver diseases such as hepatocellular carcinoma [21] and oesophageal varices [22], they may be proposed as biomarkers of disease severity [23].

We should not neglect that Gas6 has a great structural homology with protein $S$, an important regulator of coagulative cascade, which also shares the same receptors. Therefore, the system has been explored in the context of thromboembolic but its role in clinical setting is under investigation $[24,25]$.

Finally, an overactivation of the system has been associated to several solid and hematological neoplastic conditions and identified as a potential negative prognostic biomarker [26-29]. 
However, in all these conditions, the altered plasmatic concentration of Gas6 and its receptors does not seem to be only an epiphenomenon, but rather to contribute to disease pathogenesis. This is why, targeting TAM is a novel strategy proposed for different human diseases. Recently, Espindola et al. [30] have demonstrated that both Gas6 and Axl expressions are enhanced in patients with idiopathic pulmonary fibrosis (IPF); interestingly, specifically targeting Gas6/Axl interaction significantly inhibited the synthetic, migratory, and proliferative properties of IPF fibroblasts and prevented the development of pulmonary fibrosis in a murine model. Consistently, the blockade of Gas6/Axl axis is associated to a reduced collagen deposition and liver fibrosis in a murine model of Ccl-4-induced liver disease [31]. These findings support the idea that Gas6/TAM system is a promising target of antifibrotic treatments. This is not surprising, considering that tyrosine kinase inhibition is a common strategy in oncology as well; consistently, TAM receptor blockade has been already proposed for different neoplastic conditions [32-35].

In conclusion, a deeper knowledge of this relatively novel and unexplored system might contribute to clarify the pathogenetic mechanisms underlying the development of different human diseases and, potentially, to make available novel promising therapeutic tools.

\section{Conflicts of Interest}

The authors have no conflict of interest related to this publication.

\section{Pier Paolo Sainaghi Mattia Bellan Alessandra Nerviani}

\section{References}

[1] G. Manfioletti, C. Brancolini, G. Avanzi, and C. Schneider, "The protein encoded by a growth arrest-specific gene (Gas6) is a new member of the vitamin $\mathrm{K}$-dependent proteins related to protein $\mathrm{S}$, a negative coregulator in the blood coagulation cascade," Molecular and Cellular Biology, vol. 13, no. 8, pp. 4976-4985, 1993.

[2] G. C. Avanzi, M. Gallicchio, G. Cavalloni et al., "Gas6, the ligand of Axl and Rse receptors, is expressed in hematopoietic tissue but lacks mitogenic activity," Experimental Hematology, vol. 25, no. 12, pp. 1219-1226, 1997.

[3] M. G. Melaragno, D. A. Wuthrich, V. Poppa et al., "Increased expression of Axl tyrosine kinase after vascular injury and regulation by $\mathrm{G}$ protein-coupled receptor agonists in rats," Circulation Research, vol. 83, no. 7, pp. 697-704, 1998.

[4] K. Nagata, K. Ohashi, T. Nakano et al., "Identification of the product of growth arrest-specific gene 6 as a common ligand for Axl, Sky, and Mer receptor tyrosine kinases," Journal of Biological Chemistry, vol. 271, no. 47, pp. 30022-30027, 1996.

[5] J. P. O'Bryan, Y. W. Fridell, R. Koski, B. Varnum, and E. T. Liu, "The transforming receptor tyrosine kinase, Axl, is posttranslationally regulated by proteolytic cleavage," Journal of Biological Chemistry, vol. 270, no. 2, pp. 551-557, 1995.

[6] E. Thorp, T. Vaisar, M. Subramanian, L. Mautner, C. Blobel, and I. Tabas, "Shedding of the Mer tyrosine kinase receptor is mediated by ADAM17 protein through a pathway involving reactive oxygen species, protein kinase $\mathrm{C} \delta$, and $\mathrm{p} 38$ mitogenactivated protein kinase (MAPK)," Journal of Biological Chemistry, vol. 286, no. 38, pp. 33335-33344, 2011.

[7] J. H. M. van der Meer, T. van der Poll, and C. van 't Veer, "TAM receptors, Gas6, and protein S: roles in inflammation and hemostasis," Blood, vol. 123, no. 16, pp. 2460-2469, 2014.

[8] C. Schneider, R. M. King, and L. Philipson, "Genes specifically expressed at growth arrest of mammalian cells," Cell, vol. 54, no. 6, pp. 787-793, 1988.

[9] G. Zizzo, B. A. Hilliard, M. Monestier, and P. L. Cohen, "Efficient clearance of early apoptotic cells by human macrophages requires M2c polarization and MerTK induction," Journal of Immunology, vol. 189, no. 7, pp. 3508-3520, 2012.

[10] F. Alciato, P. P. Sainaghi, D. Sola, L. Castello, and G. C. Avanzi, "TNF- $\alpha$, IL-6, and IL-1 expression is inhibited by GAS6 in monocytes/macrophages," Journal of Leukocyte Biology, vol. 87 , no. 5 , pp. 869-875, 2010.

[11] M. Bellan, M. G. Cittone, S. Tonello et al., "Gas6/TAM system: a key modulator of the interplay between inflammation and fibrosis," International Journal of Molecular Sciences, vol. 20, no. 20, p. 5070, 2019.

[12] M. Bellan, M. Pirisi, and P. P. Sainaghi, "The Gas6/TAM system and multiple sclerosis," International Journal of Molecular Sciences, vol. 17, article 1807, 2016.

[13] P. P. Sainaghi, L. Collimedaglia, F. Alciato et al., "Growth arrest specific gene 6 protein concentration in cerebrospinal fluid correlates with relapse severity in multiple sclerosis," Mediators of Inflammation, vol. 2013, Article ID 406483, 7 pages, 2013.

[14] P. P. Sainaghi, L. Collimedaglia, F. Alciato et al., "Elevation of Gas6 protein concentration in cerebrospinal fluid of patients with chronic inflammatory demyelinating polyneuropathy (CIDP)," Journal of the Neurological Sciences, vol. 269, no. 12, pp. 138-142, 2008.

[15] P. P. Sainaghi, M. Bellan, F. Lombino et al., "Growth arrest specific 6 concentration is increased in the cerebrospinal fluid of patients with Alzheimer's disease," Journal of Alzheimer's Disease, vol. 55, no. 1, pp. 59-65, 2017.

[16] C. S. Wu, C. Y. Hu, H. F. Tsai et al., "Elevated serum level of growth arrest-specific protein 6 (Gas6) in systemic lupus erythematosus patients is associated with nephritis and cutaneous vasculitis," Rheumatology International, vol. 34, no. 5, pp. 625629, 2014.

[17] L. Ballantine, A. Midgley, D. Harris, E. Richards, S. Burgess, and M. W. Beresford, "Increased soluble phagocytic receptors sMer, sTyro3 and sAxl and reduced phagocytosis in juvenileonset systemic lupus erythematosus," Pediatric Rheumatology Online Journal, vol. 13, no. 1, p. 10, 2015.

[18] L. Xu, F. Hu, H. Zhu et al., "Soluble TAM receptor tyrosine kinases in rheumatoid arthritis: correlation with disease activity and bone destruction," Clinical and Experimental Immunology, vol. 192, no. 1, pp. 95-103, 2018.

[19] B. Qin, J. Wang, N. Ma et al., "The association of Tyro3/Axl/Mer signaling with inflammatory response, disease activity in patients with primary Sjogren's syndrome," Joint, Bone, Spine, vol. 82, no. 4, pp. 258-263, 2015.

[20] M. Bellan, G. Pogliani, C. Marconi et al., "Gas6 as a putative noninvasive biomarker of hepatic fibrosis," Biomarkers in Medicine, vol. 10, no. 12, pp. 1241-1249, 2016. 
[21] K. Staufer, M. Dengler, H. Huber et al., "The non-invasive serum biomarker soluble Axl accurately detects advanced liver fibrosis and cirrhosis," Cell Death \& Disease, vol. 8, no. 10, article e3135, 2017.

[22] M. Bellan, P. P. Sainaghi, M. T. Minh et al., "Gas6 as a predictor of esophageal varices in patients affected by hepatitis $\mathrm{C}$ virus related-chronic liver disease," Biomarkers in Medicine, vol. 12, no. 1, pp. 27-34, 2018.

[23] M. Bellan, L. M. Castello, and M. Pirisi, "Candidate biomarkers of liver fibrosis: a concise, Pathophysiology-oriented Review," Journal of Clinical and Translational Hepatology, vol. 6, no. 3, pp. 317-325, 2018.

[24] A. Schnegg-Kaufmann, S. Calzavarini, A. Limacher et al., "A high Gas6 level in plasma predicts venous thromboembolism recurrence, major bleeding and mortality in the elderly: a prospective multicenter cohort study," Journal of Thrombosis and Haemostasis, vol. 17, no. 2, pp. 306-318, 2019.

[25] P. P. Sainaghi, F. Alciato, S. Carnieletto et al., "Gas6 evaluation in patients with acute dyspnea due to suspected pulmonary embolism," Respiratory Medicine, vol. 103, no. 4, pp. 589594, 2009.

[26] P. P. Sainaghi, L. Castello, L. Bergamasco, M. Galletti, P. Bellosta, and G. C. Avanzi, "Gas6 induces proliferation in prostate carcinoma cell lines expressing the Axl receptor," Journal of Cellular Physiology, vol. 204, no. 1, pp. 36-44, 2005.

[27] J. Han, R. Tian, B. Yong et al., "Gas6/Axl mediates tumor cell apoptosis, migration and invasion and predicts the clinical outcome of osteosarcoma patients," Biochemical and Biophysical Research Communications, vol. 435, no. 3, pp. 493-500, 2013.

[28] J. S. Waizenegger, I. Ben-Batalla, N. Weinhold et al., "Role of growth arrest-specific gene 6-Mer axis in multiple myeloma," Leukemia, vol. 29, no. 3, pp. 696-704, 2015.

[29] H. J. Lee, Y. M. Jeng, Y. L. Chen, L. Chung, and R. H. Yuan, "Gas6/Axl pathway promotes tumor invasion through the transcriptional activation of Slug in hepatocellular carcinoma," Carcinogenesis, vol. 35, no. 4, pp. 769-775, 2014.

[30] M. S. Espindola, D. M. Habiel, R. Narayanan et al., “Targeting of TAM receptors ameliorates fibrotic mechanisms in idiopathic pulmonary fibrosis," American Journal of Respiratory and Critical Care Medicine, vol. 197, no. 11, pp. 1443-1456, 2018.

[31] C. Bárcena, M. Stefanovic, A. Tutusaus et al., "Gas6/Axl pathway is activated in chronic liver disease and its targeting reduces fibrosis via hepatic stellate cell inactivation," Journal of Hepatology, vol. 63, no. 3, pp. 670-678, 2015.

[32] I. Ben-Batalla, A. Schultze, M. Wroblewski et al., "Axl, a prognostic and therapeutic target in acute myeloid leukemia mediates paracrine crosstalk of leukemia cells with bone marrow stroma," Blood, vol. 122, no. 14, pp. 2443-2452, 2013.

[33] C. D. May, J. Garnett, X. Ma et al., "AXL is a potential therapeutic target in dedifferentiated and pleomorphic liposarcomas," BMC Cancer, vol. 15, no. 1, p. 901, 2015.

[34] E. Martinelli, G. Martini, C. Cardone et al., "AXL is an oncotarget in human colorectal cancer," Oncotarget, vol. 6, no. 27, pp. 23281-23296, 2015.

[35] D. J. Pinato, M. W. Brown, S. Trousil et al., "Integrated analysis of multiple receptor tyrosine kinases identifies Axl as a therapeutic target and mediator of resistance to sorafenib in hepatocellular carcinoma," British Journal of Cancer, vol. 120, no. 5, pp. 512-521, 2019. 